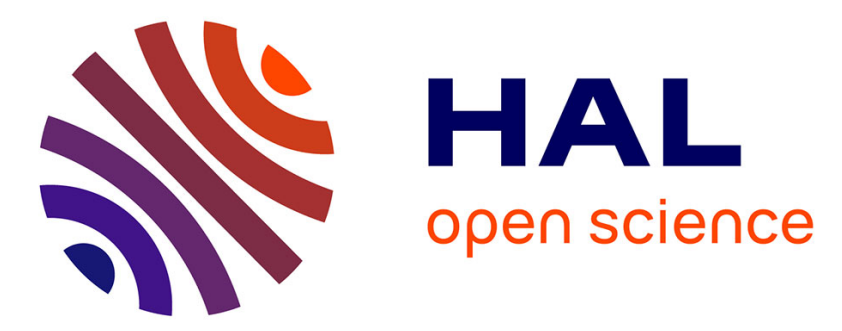

\title{
Design of micro-fabricated thermal flow-rate sensor for water network monitoring
}

Shaun Ferdous, Hugo Regina, Frédéric Marty, E. Nefzaoui, Tarik Bourouina, William Cesar

\section{> To cite this version:}

Shaun Ferdous, Hugo Regina, Frédéric Marty, E. Nefzaoui, Tarik Bourouina, et al.. Design of micro-fabricated thermal flow-rate sensor for water network monitoring. 19th Symposium on Design, Test, Integration \& Packaging of MEMS and MOEM (DTIP 2017), May 2017, Bordeaux, France. 10.1109/DTIP.2017.7984474 . hal-01578598

\section{HAL Id: hal-01578598 \\ https://hal.science/hal-01578598}

Submitted on 29 Aug 2017

HAL is a multi-disciplinary open access archive for the deposit and dissemination of scientific research documents, whether they are published or not. The documents may come from teaching and research institutions in France or abroad, or from public or private research centers.
L'archive ouverte pluridisciplinaire HAL, est destinée au dépôt et à la diffusion de documents scientifiques de niveau recherche, publiés ou non, émanant des établissements d'enseignement et de recherche français ou étrangers, des laboratoires publics ou privés. 


\section{Design of micro-fabricated thermal flow-rate sensor for water network monitoring}

\author{
Ferdous Shaun*, Hugo Regina, Frederic Marty, Elyes \\ Nefzaoui, Tarik Bourouina \\ Université Paris-Est, ESYCOM-Lab, ESIEE-Paris \\ Noisy-Le-Grand, France \\ *ferdousjahan.shaun@esiee.fr
}

\begin{abstract}
We report on micro-machined flow-rate sensors as part of autonomous multi-parameter sensing devices for water network monitoring. Three different versions of the flow-rate sensors have been designed, fabricated and experimentally characterized. Those sensors are made of identical micrometric platinum resistors deposited on two different substrates- glass and silicon with and without insulation layer. The sensors were tested under the anemometric operating scheme. They were characterized under a water velocity range from 0 to $3.68 \mathrm{~m} / \mathrm{s}$. We highlight the fact that the glass substrate device is more sensitive and less power-consuming than the silicon one under the identical operating condition, which requires further design strategies when using silicon as the substrate material. Experimental results are analyzed with respect to CFD simulations with the Finite Element Method.
\end{abstract}

Keywords-Sensor; MEMS; Flow-rate; Thermal sensor; Micromachined sensor; Water Network Monitoring

\section{INTRODUCTION}

Flow rate measurement is very important in different aspects of industrial and engineering processes, Environment monitoring[1], Biology[2] and Biomedical fields[3], [4]. For instance, flow rate measurement is highly important for water distribution systems not only for measuring water consumption but also for leakage detection. Generally, a water distribution system is a vast network. Consequently, a finely meshed monitoring system based on a sensor network can be quite expensive. Micro-fabrication technologies offer solutions for such a problem with a good meshing/cost tradeoff through cheap lab on chip sensors, which can be deployed in large number.

During the last decades, the advancement of microfabrication techniques enabled the design of low-cost miniaturized sensors for different applications [5], [6]. They offer several advantages: compactness, low cost and low power consumption. In addition, mass production can be considered thanks to the wide range of flow rates that can be covered by these sensors, from $\mu 1 / \mathrm{min}$ to liter/min[2], [7]. Thermal flow rate-senor can be categorized into three categories: calorimetric, time-of-flight (TOF) and hot-wire (anemometric). The calorimetric sensor detects the fluid flow by measuring temperature distribution around the heater by two sensing resistors. Sensing resistors measure the thermal asymmetry due to the water flow. The TOF method is based on measuring the

\author{
William Cesar \\ Fluigent Smart Microfluidics \\ 1, Mail du Professeur Georges Mathé \\ Villejuif, France
}

transition time of a thermal pulse from a heater to a set distance. Hot-wire anemometer flow-rate sensor is made of a resistive wire, which transfers heat to the surrounding fluid. Flow-rate is detected by extracting, through temperature measurement, the amount of convective heat loss from the resistive heater, which is proportional to the fluid flow [1], [7]. This paper reports on experimental and numerical comparison of three micro-machined thermal flow-rate sensors operated in anemometric mode. First, we will present the fabrication process and the experimental and numerical methods. Then, results are reported as well as a brief discussion.

\section{METHOD}

\section{A. Fabrication}

The sensors were fabricated on three different substrates: glass, silicon and a silicon membrane. These three configurations will be referred to as Gl-sensor, Si-sensor and $\mathrm{Mb}$-sensor, respectively. The sensitive element is a 4-probe platinum thermistor. Platinum was chosen as a material for its excellent linearity and high TCR, which is $2.218 \times 10^{-3}{ }^{\circ} \mathrm{C}^{-1}$ in our case.

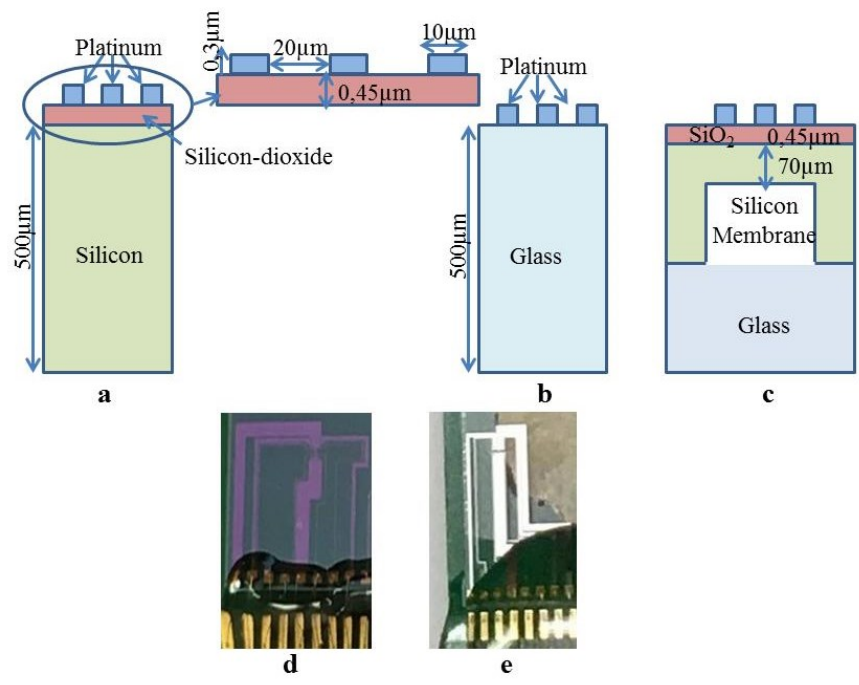

Figure 1: Schematic representation of- (a) silicon, (b) glass and (c) membrane based flow rate sensor; real fabricated sensor on (d) silicon and (e) glass substrate 
Three resistors were deposited on each substrate to enable different operating schemes. Only one resistor is used in the present study. The geometrical dimensions of the three configurations are presented in Figure 1. For Si-sensor, a 0.45 $\mu$ m-thick $\mathrm{SiO}_{2}$ insulation layer is introduced between the resistors and the $500 \mu \mathrm{m}$-thick silicon substrate to reduce the overall device thermal conductance. The $\mathrm{SiO}_{2}$ layer was produced by thermal wet oxidation. The Pt resistors were patterned by a lift-off process following sputter-deposition. For $\mathrm{Mb}$-sensor, the $\mathrm{Pt}$ resistors were mounted on a silicon membrane resulting from backside silicon etching. The cavity depth of the membrane is nearly $500 \mu \mathrm{m}$-thick. Glass was used as a substrate under the silicon membrane support.

\section{B. Experimental Setup}

The sensor was inserted into a 32-mm diameter PCV pipe. A square-shaped plastic box with one open side was used as a water reservoir in which a variable speed water pump was submerged. A closed loop was built between the PVC pipe, the water reservoir and the pump by $16-\mathrm{mm}$ diameter flexible pipes, which were connected to the PVC by adjusters.

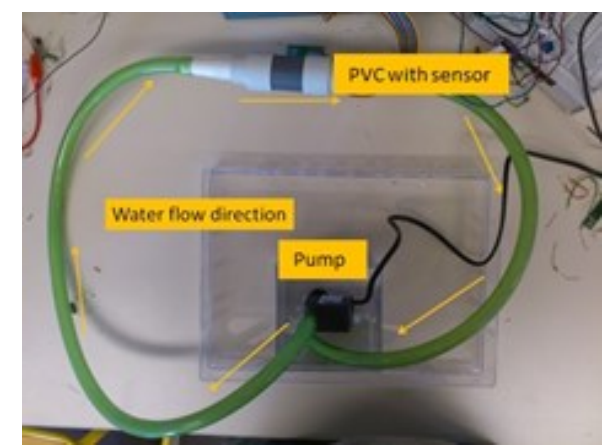

Figure 2: Experimental setup

Hot-wire anemometric operation scheme was used for velocity and flowrate measurement. To ensure a good anemometric operation, a constant current source was used to supply the current to the 4-probe heater resistor. LabVIEW was used for data acquisition. For each flow rate value the voltage drop due to the water flow, cooling was measured. The resistance drop with respect to the zero-velocity situation was then calculated and related to the temperature and hence to the fluid velocity.

\section{Simulation}

CFD numerical analysis based on finite element method was carried out to extract the effect of physical structure and material properties on the sensor performance. COMSOL Multiphysics 5.2a was used to perform the simulation using conjugate heat transfer physics; which deals with the heat transfer both in solid and fluid medium. The geometry was composed of as it is presented in Figure 1 (a), (b) and (c). The corresponding dimensions of each part of the geometry are also illustrated in the same figure. All the materials properties were exported from the COMSOL library. A parametric study was conducted for each configuration in order to study the thermal variation under water flow condition at different velocities for a given supplied power. Since the target is to implement the sensor in the real water distribution system to monitor the water network so, a larger fluidic domain was chosen to avoid the influences of fluidic boundaries on the flow-rate sensor which is closer to the real situation as well.

\section{RESULTS AND DISCUSSION}

An anemometric flow rate sensor measures a temperature drop due to a fluid flow. The velocity is then deduced from the cooling magnitude. Consequently, the sensor Joule selfheating in a non-flowing fluid is a critical parameter.

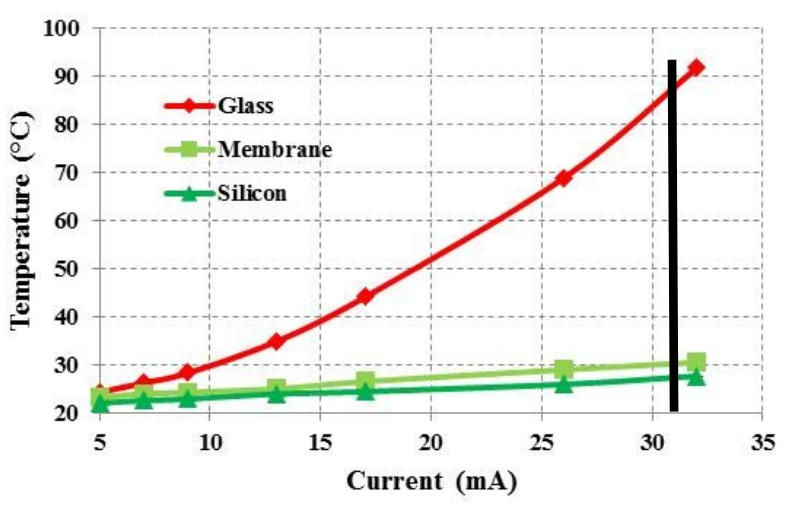

Figure 3: Joule self-heating experiment at different current intensities for corresponding three configurations

We show in Figure 3, the sensors measured temperature due to Joule self-heating in a non-flowing condition for different electric current intensities. Si-sensor and Mb-sensor show almost similar behaviors for all considered current values. A small maximal temperature increase, $5.6{ }^{\circ} \mathrm{C}$ and 7.3 ${ }^{\circ} \mathrm{C}$ for instance, is observed for $\mathrm{Si}$-sensor and $\mathrm{Mb}$-sensor respectively with a current intensity as large as $32 \mathrm{~mA}$. Glsensor exhibits a temperature increase of $67.2^{\circ} \mathrm{C}$ for the same amount of current. As a result, we can expect that the Glsensor will be sensitive to a wider flow-rate range and low power consuming under the same operating conditions. This sensitivity difference is more critical when low power consumption is targeted.

In addition, this Joule self-heating test gives the information regarding the minimal operating current for a device. It can be seen from Figure 3, the Gl-sensor can be operated efficiently with a supplied current $13 \mathrm{~mA}$. Besides, the $\mathrm{Si}$-sensor and $\mathrm{Mb}$-sensor do not reach to the optimum heated condition even with a larger supplied current as $32 \mathrm{~mA}$. An experimental sensitivity study was performed on Si-sensor with respect to the supplied current, i.e. the consumed power. For a given supplied current, the sensor surrounding temperature is varied between 20 to $90^{\circ} \mathrm{C}$ with a step of $5^{\circ} \mathrm{C}$. The voltage and resistance variations are then measured (Figure 4). 


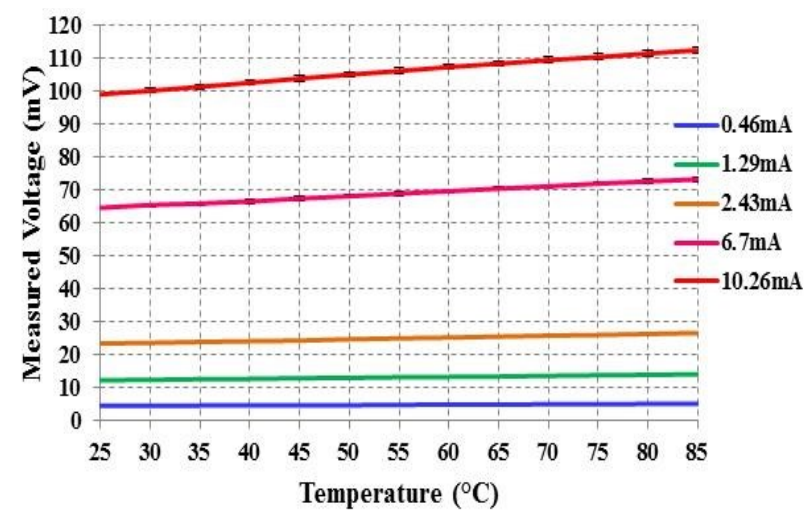

Figure 4: Measured voltage at the resistor terminals for different temperatures and different electric currents

A very small temperature dependence is observed for currents smaller than $6.7 \mathrm{~mA}$. Due to the conductive heat loss through the silicon substrate, the heater resistor was not heated enough for the small amount of supplied current and consequently, the $\mathrm{Si}$-sensor was not sensitive to temperature differences as large as $5^{\circ} \mathrm{C}$, hence to a big range of small flow velocities, for low current values.

Another experiment was conducted in order to study the thermal sensitivity of the three sensors with respect to water flow, which is demonstrated in Figure 5.
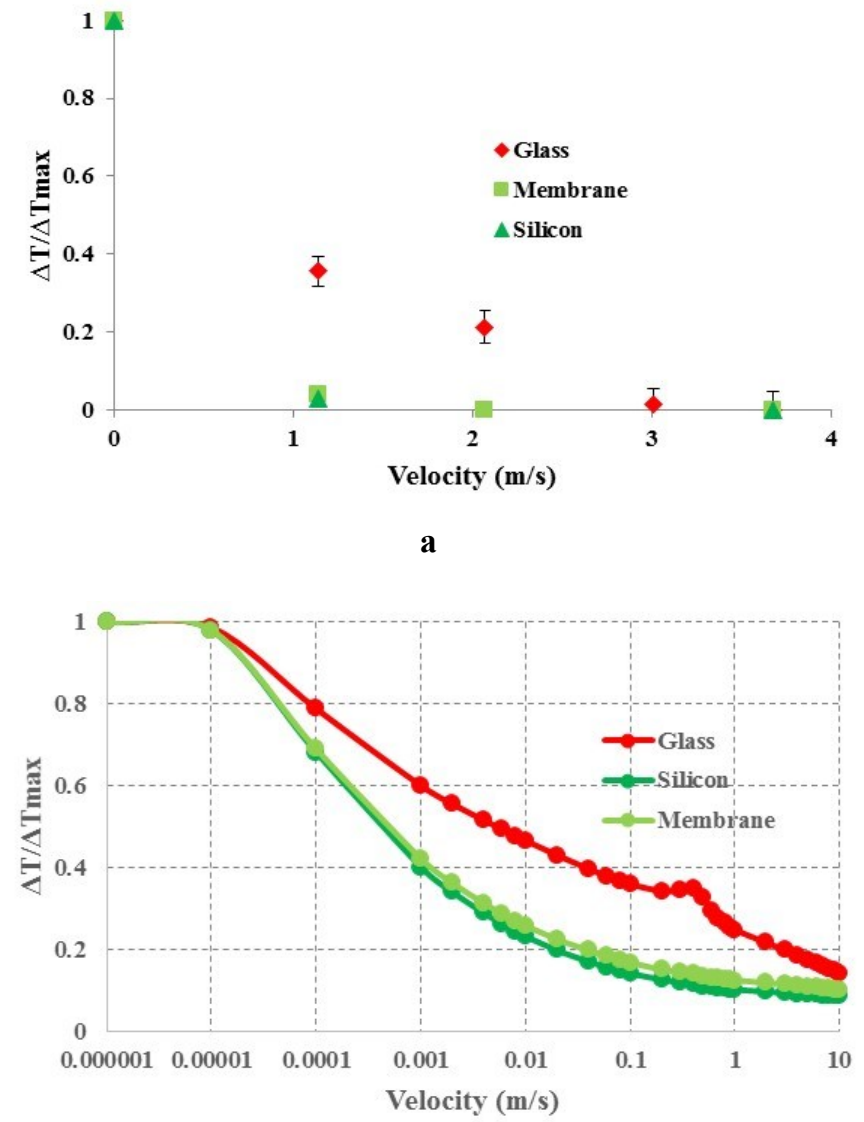

b
Figure 5: Non-dimensional temperature drop due to convective cooling of glass, membrane and silicon flow-rate sensor (a) experimental and (b) numerical results; $\Delta T_{\max }$ is equal to $13.48{ }^{\circ} \mathrm{C}, 1.08{ }^{\circ} \mathrm{C}$ and $0.54{ }^{\circ} \mathrm{C}$ for glass, membrane and silicon substrate sensor respectively for the experimental results

In Figure 5, we report non-dimensional temperature variation both experimental (Figure 5a) and numerical (Figure 5b) for the three sensors, which is defined as $\Delta \mathrm{T} / \Delta \mathrm{T}_{\max }$ at different flow velocities and electric power supply. $\Delta \mathrm{T}$ is the difference between the sensor's heater resistor temperature and room temperature at a given velocity and $\Delta \mathrm{T}_{\max }$ is the same temperature difference at zero velocity. The value of $\Delta \mathrm{T} / \Delta \mathrm{T}_{\max }$ quantifies the fluid flow cooling effect and this value indicates the sensitivity level and turndown ratio of the sensor as well, the smaller $\Delta T / \Delta \mathbf{T}_{\max }$, the more sensitive the sensor. It can be seen from the Figure 5a, only Gl-sensor shows the sensitivity for a large velocity range from 0 to $3.68 \mathrm{~m} / \mathrm{s}$, which is deducible from the Joule self-heating test. On the other hand, $\mathrm{Si}$-sensor and $\mathrm{Mb}$-sensor reached at saturation when the velocity exceeds $1.14 \mathrm{~m} / \mathrm{s}$. This experiment was done at $32 \mathrm{~mA}$ current supply to ensure the maximum self-heating for the three devices. Presented numerical results in Figure $\mathbf{5 b}$, which express the same meaning as experimental results from the same, comparatively Gl-sensor is more sensitive to wider flow-rate range than the $\mathrm{Si}$ and $\mathrm{Mb}$-sensor.

The illustration of non-dimensional temperature variation based on the numerical analysis (Figure 5b), shows the unrestrained trend at a certain velocity range (from $0.2 \mathrm{~m} / \mathrm{s}$ to $0.4 \mathrm{~m} / \mathrm{s}$ ) for Gl-sensor. This is actually happened due to the reverse flow at the vicinity of the heater resistor. This reverse flow brought back the hot water to the resistor and as a consequence, rather than decreasing the heater temperature it was increasing within that velocity range. The Same scenario also happened for $\mathrm{Si}$ and $\mathrm{Mb}$-sensors, but they showed the monotonous trend for the whole velocity range since the heater resistor was not heated up to the same level as it was for glass substrate based configuration.

The numerical and experimental study showed that the substrate thermal conductance is the parameter governing $\Delta T_{\max }$ and $\Delta T / \Delta T_{\max }$ for a given power supply value. Since the thermal conductivity of silicon is relatively higher than that of the glass. As a result, with the same amount of power supply we just only heated the resistor of a glass substrate based flowrate sensor whereas we were heated not only the resistor but also the substrate as well when the sensor was fabricated on bulk silicon. Although, introduced silicon membrane diminish the conductive heat loss through the substrate but not significantly which may lead to an eminent thermal flow-rate sensor. So, it is the key parameter to obtain a sensitive and low power consuming anemometric flow-rate sensors. 


\section{CONCLUSION}

Three micro-machined flow-rate sensors for autonomous water network monitoring devices have been designed, fabricated and experimentally characterized. Their main difference appears in the used substrate material. We show experimentally and numerically that the glass substrate device is far more sensitive and less power consuming. We also show that the key parameter for such performances is its low thermal conductivity. However, large thermal conductivity materials such as silicon can be needed for co-integration of different sensors in lab-on-chip devices which increase power consumption and reduce sensitivity. We show that a simple geometric optimization such as the use of a silicon membrane is insufficient to overcome this problem. More complex geometries and strategies which reduce the overall device thermal conductance are then needed to obtain energy efficient and sensitive devices.

\section{ACKNOWLEDGMENT}

This work has received funding from the European Union's H2020 Programme for research, technological development and demonstration under grant agreement No644852.

Part of this work had the support of the National Research Agency (ANR) in the frame of the EquipEx project SENSECITY of the Programme Investissement d'Avenir (PIA), involving IFSTTAR and ESIEE Paris as founding members of the consortium.

Fabrication of the chips was done in the cleanroom facilities of ESIEE Paris, whose technical staff is deeply acknowledged.

\section{REFERENCES}

[1] J. T. W. Kuo, L. Yu, and E. Meng, "Micromachined Thermal Flow Sensors-A Review," Micromachines, vol. 3, no. 3, pp. 550-573, Jul. 2012.

[2] R. Vilares et al., "Fabrication and testing of a SU-8 thermal flow sensor," Sens. Actuators B Chem., vol. 147, no. 2, pp. 411-417, Jun. 2010.

[3] S. Wu, Q. Lin, Y. Yuen, and Y.-C. Tai, "MEMS flow sensors for nanofluidic applications," Sens. Actuators Phys., vol. 89, no. 1-2, pp. 152158, Mar. 2001

[4] C.-H. Wu, D. Kang, P.-H. Chen, and Y.-C. Tai, "MEMS thermal flow sensors," Sens. Actuators Phys., vol. 241, pp. 135-144, Apr. 2016.

[5] H. Fujita, "A decade of MEMS and its future," in , Tenth Annual International Workshop on Micro Electro Mechanical Systems, 1997. MEMS '97, Proceedings, IEEE, 1997, pp. 1-7.

[6] Y. Yamazaki, K. Yoshikawa, and K. Sato, "A MEMS flow sensor applied in a variable-air-volume unit in a building air-conditioning system," Sens. Actuators Phys., vol. 189, pp. 212-217, Jan. 2013.

[7] W.-C. Lin and M. A. Burns, "Low-power micro-fabricated liquid flowrate sensor," Anal. Methods, vol. 7, no. 9, pp. 3981-3987, Apr. 2015. 